\title{
Structural Fire Resistance on a Shear Connection between a Beam and Column Fastened by High Strength Bolts
}

\author{
Fuminobu Ozaki ${ }^{1}$ and Takeo Hirashima ${ }^{2}$ \\ ${ }^{1}$ Tokyo University of Science \\ ${ }^{2}$ Chiba University
}

Keywords : High Strength bolt, Shear Connection between a Beam and Column, Fire resistance performance, Ultimate temperature, Finite element method

\section{INTRODUCTION}

The fire resistance performance of the steel frame that has a shear connection (pin connection) between a beam and column by high strength bolts was examined in this research. The shear connection between a beam and column was used in a frame with braces and so on. And shear force on the beam is transmitted through the high strength bolt in the web of the beam. The number of the bolts installed into the frame with braces is smaller than that installed into a rigid frame because high strength bolts are not installed on a flange of beam in the frame with braces. Strong thermal stress (axial compressive force) acts on these few bolts in web in fire, and the bolts may fracture at the early stage of fire during heating. In order to examine this problem, the ultimate temperatures of steel frames with the shear connection between a beam and column are clarified using the finite-element analysis [1] in which the high temperature mechanical characteristic of the high strength bolt obtained from previous researches was included.

\section{ANALYTICAL MODEL}

Figure 1 shows the frame model for analysis. A shear-connection part was installed in a beam end. The temperatures of the black members and the shear-connection shown in Figure 1 rised uniformly.

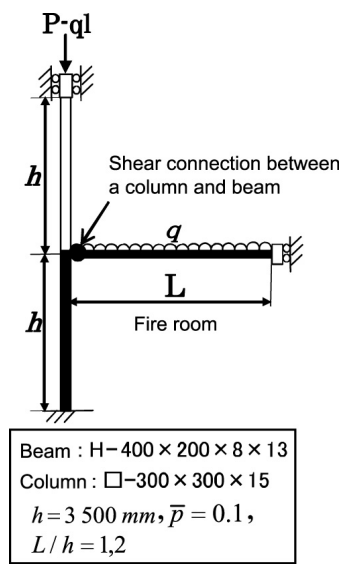

Figure 1 Analysis model 
It was determined that the number of the bolts installed into the connection fulfilled the following Equation 1.

$$
A_{B w} q_{b y}=A_{e w} F_{y} / \sqrt{3}
$$

$A_{B w}$ : sum of sectional area of the bolts installed into web (single shearing)

$q_{b y}:$ slip strength of high strength bolt at normal temperature (F10T)

$A_{\text {ew }}$ : sectional area of the web except the bolt holes

$F_{y}$ : yield strength of the beam at normal temperatures

The shear connection needed three bolts with a diameter of $21.5 \mathrm{~mm}$ in the web by the Equation 1 and they were attached. Figure 2 shows the details of the connection. The steel grade of the column and the beam was SS400 and the stress-strain relation at high temperatures proposed by AIJ [2] was used in this analysis.

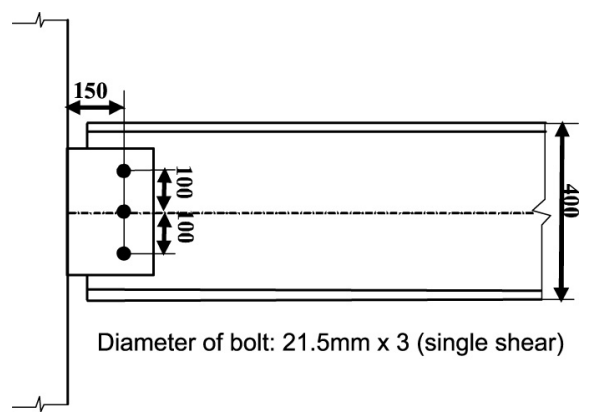

Figure 2 Part of the shear connection between a column and beam used in the analysis

And, the high strength bolt was F10T, and the decrease rate of strength at high temperature was shown in Figure 3. This broken line in Figure 3 approximately agreed with the value $\left(\sigma_{b u}^{A V}\right.$ (average)- $3 \times \sigma$ (standard deviation)) of past coupon test results.[3-7] Figure 4 showed the shear stress $\tau$-shear deformation $\Delta$ relations at high temperature for the high strength bolts. [8] The maximum shear strength of the high strength bolt at each temperatures was in agreement with $0.6 \sigma \mathrm{k}(\mathrm{T})$. Here, $\sigma$ was the maximum tensile strength $\left(=1000 \mathrm{~N} / \mathrm{mm}^{2}\right)$ of the high strength bolt at room temperature. Figure 4 showed that the bolts of $400^{\circ} \mathrm{C}$ or more did not fracture immediately after the stress reached the maximum shear strength. After that, they had the residual shear strength with increase of the deformation. The $\tau-\Delta$ relation as shown in Figure 4 was set up because these phenomena had been observed in the past experiment [5, 9], and the elongations that the bolts fractured over $400^{\circ} \mathrm{C}$ increased greatly in the coupon tests for the bolts. 


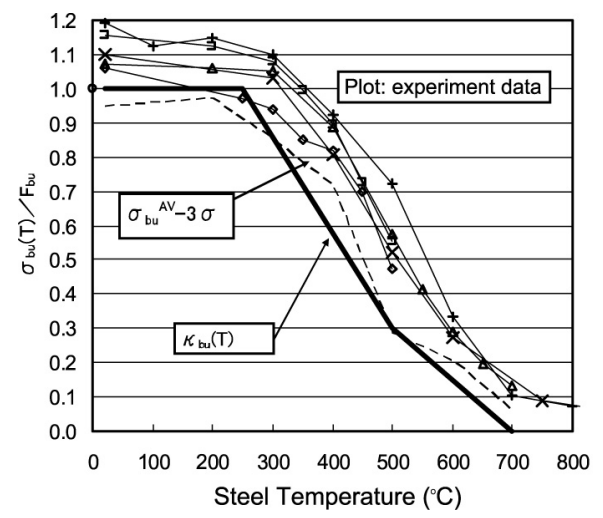

Figure 3 Decreasing rate of strength F10T

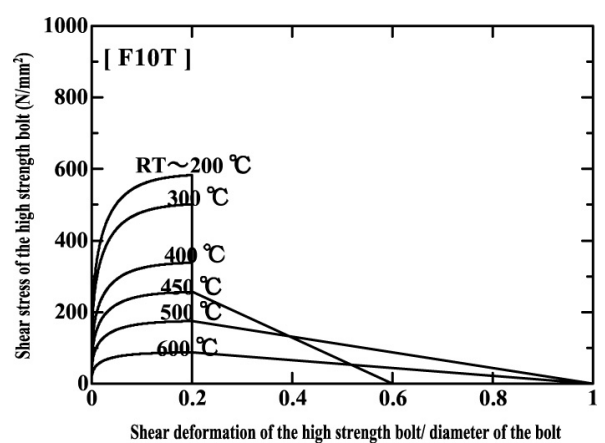

Figure $4(t \sim \Delta)$ relation of F10T at high temperature

\section{ANALYSIS RESULTS AND CONSIDERATION}

Figure 5 shows the analysis results. The vertical axis and horizontal axis in the figure were the temperature and the nondimensional value $\widetilde{q}\left(=_{q L^{2} / 2 \bar{M}_{p B}}\right)$ of load on the beam respectively. Each plot in the figure was the ultimate temperature obtained from the numerical analysis. On the other hand, the lines were the theoretical ultimate temperatures. Among these lines, the solid line was the fundamental ultimate temperature [2] that the beam end was assumed to be a pin connection, and the dashed line and the dash dotted line were the shear ultimate temperatures [8] of the connection with $\mathrm{L} / \mathrm{h}=1$ and 2 , respectively.

Figure 5 shows that the ultimate temperatures of the analysis $(\circ, \Delta)$ is greatly lower than the fundamental ultimate temperature (solid line). When L/h was $2(\Delta)$, the decrease of the ultimate temperature became larger because the thermal stress in the beam became very strong. Especially, the deflection of the beam with small beam load $\tilde{q}$ was small and the thermal stress in the beam was not released easily. Therefore, the high strength bolts in the connection fractured at the early stage by thermal stress in these frames. 
On the other hand, the bending moment that the web bolts bore was large in the frame with the heavy load on the beam of $\mathrm{L} / \mathrm{h}=2$. Therefore, the web bolt of the lower end that the shear force by the bending compression (direction that the beam shrank), and the shear force by heat stress for the compressive direction were loaded, fractured about $400^{\circ} \mathrm{C}$ or less $(\times)$. However, the web bolt of the upper end did not fracture because the shear force by the bending tension (direction that the beam extended) decreased .the shear force for the tensile direction. When the lower end bolt fractured, the thermal stress was released rapidly. After that, only the upper end bolt bore the load on the beam. In this case, the ultimate temperature of the frame rose further even if the lower end bolt fractured.

Figure 6 shows the analysis results that the number of the bolts twice as many as that in the analysis shown in Figure 5. Figure 6 meant that the fire resistance performance might improve considerably if the number of the bolts doubled. For example, the row of the bolts in the web was increased by one row. But, the ultimate temperatures of the frame with small $\tilde{q}$ were a little less than the fundamental ultimate temperature.

Figure 7 shows the analysis results that the temperatures of the column and the beam rose uniformly and the temperatures of the bolts were kept under $250^{\circ} \mathrm{C}$. Namely, the strength of the bolts did not decrease.

All the collapse modes of the frame became the overall buckling of the column, without fracturing the web bolts by the thermal stress in the beam.

In this research, even though the $\tau-\Delta$ relation of the high strength bolt was given as the solid line in Figure 4, it is necessary to inquire still in detail. A still more detailed examination was required when the relation was formulized. And, the examination for the inner span fire in a frame was necessary because the extension of a beam was restricted strongly by surrounding members.

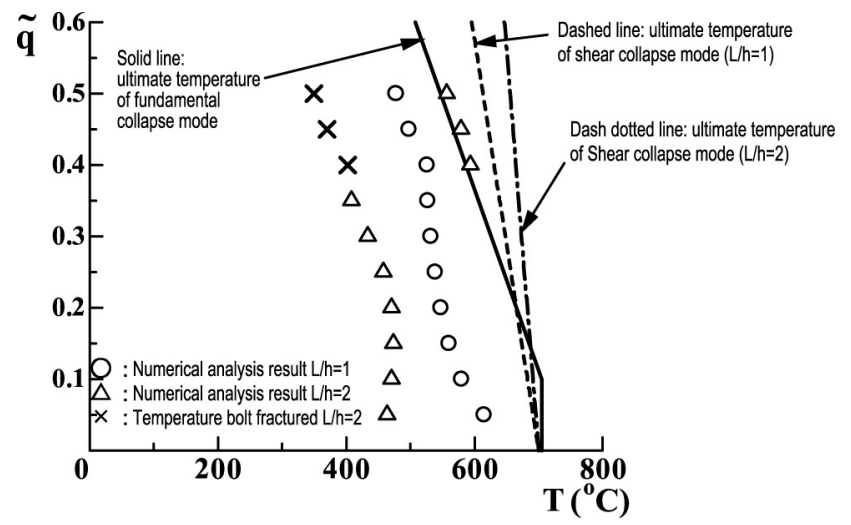

Figure 5 Numerical analysis results( the connection fulfilled the equation (1)) 


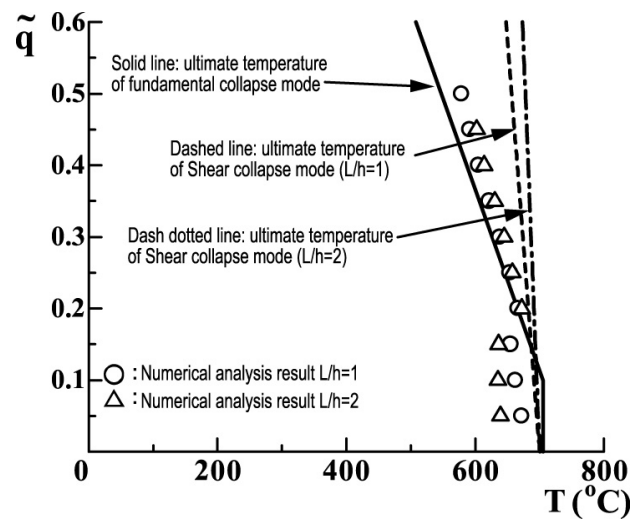

Figure 6 Numerical analysis results(When the amount of the bolts were twice as many.)

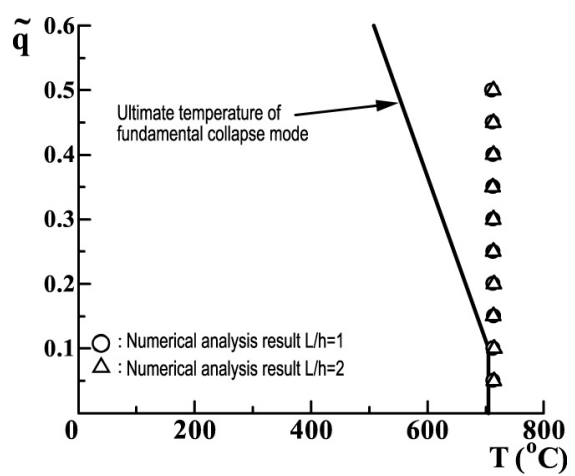

Figure 7 Numerical analysis results(When the temperature of the bolts were $250^{\circ} \mathrm{C}$ or less.)

\section{REFERENCES}

1. Ozaki F., Suzuki H. and Ide Y., "Ultimate Temperature of Steel frames Subject to Fire -Part20 Ultimate Temperature of Steel Frames with Joints-", Summaries of technical papers of Annual Meeting Architectural Institute of Japan. A-2, Fire safety, off-shore engineering and architecture, information systems technology, pp. 147-148, 1997 (in Japanese)

2. Architectural Institute of Japan, "Recommendation for Fire Resistant Design of Steel Structure", 1999 (in Japanese)

3. Igarashi S., Wakiyama K., Tatsumi A. and Sakurai H., "Research on Mechanical Properties of High-Strength Bolt at Elevated Temperature Part 1", Proceeding of the 2nd Architectural Research Meetings, Kinki Chapter Architectural Institute of Japan, 1977 (in Japanese)

4. Kokubo I. Tanaka A. and Furumura F., "Mechanical Properties of High-Strength Bolt under High Temperatures Part 1", Transactions of the Architectural Institute of Japan, No.309, pp.21-28, 1981 (in Japanese) 
5. Hirashima T., Orimo T., KikutabS., Takahashi K., Hori A., Nakagome A., Matsudo M., Suzuki T., Yodhida M., Yamaouchi H. Nakamura K., Uesugi H. and Saito H., "Experiment of Ultimate Strength of High Strength Bolt at Elevated Temperature", Summaries of technical papers of Annual Meeting Architectural Institute of Japan. A-2, Fire safety, off-shore engineering and architecture, information systems technology, pp. 39-42, 1999 (in Japanese)

6. Kodaira A. Fujinaka H. and Takada T., "Strength of High Strength Bolt at Elevated Temperature and after Cooling Down, Summaries of technical papers of Annual Meeting Architectural Institute of Japan. A-2, Fire safety", off-shore engineering and architecture, information systems technology, pp.117-118, 2000 (in Japanese)

7. Abe T., Kameda A., Hamada N., Fujimoto K., Hirashima T. And Uesugi H., "Fire Resistive Performance of High Strength bolted Joint Part 1", Proceedings of JAFSE Annual Symposium 2006, Japan Association for Fire Science and Engineering, pp.62-65, 2006 (in Japanese)

8. Ozaki F. and Suzuki H., "Ultimate temperatures of Steel Frames with High Strength Bolted Beam Joints Subjected to Fire", Journal of structural and construction engineering. Transactions of AIJ, No.547, pp.207-214, 2001 (in Japanese)

9. Fujimoto K., Hamada N., Segawa H., Hirashima T., Uesugi H. and Abe T., "Fire Resistive Performance of High Strength bolted Joint Part 2", Proceedings of JAFSE Annual Symposium 2006, Japan Association for Fire Science and Engineering, pp.65-69, 2006 